\title{
Increasing Technical Performance through Style Improvement Exercise on Swimming Athlete
}

\author{
Bambang Sutiyono', Hari Setijono ${ }^{2}$, Tandiyo Rahayu ${ }^{3}$, Hari A. Rachman ${ }^{4}$ \\ ${ }^{1234}$ Graduate, State University of Semarang, Kelud Utara III Gajahmungkur, Semarang, 50228 \\ Corresponding email: bangpora@yahoo.com
}

\begin{abstract}
The purpose of this study is to produce a design process improvement training stroke that can be used to enhance and improve the technical problems in swimmer Nasional Training Camp the 27th Southeast Asian Games 2013. Samples are 2 swimmer Nasional Training Camp the 27th Southeast Asian Games 2013. Instruments consists of shark fin drill to fix the rolling body, thumb touch the axilla drill to improve recovery, and manus joint 35 degrees drill to improve the insweep. Data is processed by descriptive statistics based on visual observations. Product research found (1) shark fin drill to fix the rolling motion of the body (2) drill thumb touch the axilla can improve recovery, and (3) drill manus joint 35 degrees can improve the insweep. Need to develop new drill-drill to develop the mechanics of motion in accordance with the weaknesses, shortcomings, and mistakes athlete motion.
\end{abstract}

Keywords: shark fin, axilla, manus.

\section{Introduction}

The Indonesia Gold program, or abbreviated PRIMA, is a national program designed and implemented by the government to boost national sporting achievements in multievents at regional and international level. As proclaimed by the Ministry of Youth and Sport (Kemenpora), Indonesia is expected to be the overall champion in the SEA Games 2013 and ranked $10^{\text {th }}$ in the Asian Games 2014. At the SEA Games 2011 in Palembang, Indonesia's Pool Team contributed 6 gold medals, and the achievement must enhanced by still honing the ability of athletes, considering the swimming pool of the contested medals amounted to 32 gold medals. In comparison to the achievements of the last five SEA Games events, the Indonesian swimming team showed fluctuations in the gold medal. The 2003 SEA Games in Vietnam collected 1 gold medal, in Filiphina in 2005 got 4 golds, in 2007 in Thailand only won 4 silver, and in 2009 in Laos won 2 gold and in 2011 in Indonesia earned 6 gold.

It is believed that in the implementation of national training, not all trainers involved in PRIMA apply science-based training principles by improving the quality of training with High Performance Program, an athlete coaching program involving all elements of training in an integrated manner. The main principles of the program include the integration of physical training, techniques, tactics and mental preparation of the champions, as well as the implementation of a performance monitoring system and mastery analysis of athlete skill in a programmable manner.

The observation of style mechanics at Pelatnas athletes found that Alexisis Wijaya and Patrisia Yosita felt body rolling movement not optimal and when the entry is still slamming. Albert Susanto acknowledges that there is a lack of both athletes but can not be optimal in dealing with the problems faced by athletes because of "lack of time". The mechanical problems of Alexis and Yosita's lack of style are improved by being reminded simultaneously during daily practice. The method contradicts Dick, which states that technical training should be given before strenuous and exhausting physical exercise. Another expert, Bompa stated that athletes should continue to work to maximize technical skills and therefore should incorporate technical elements into the overall training plan.

Learning techniques are the processes by which an athlete acquires mechanical skills, perfects skills, and then accustoms his skills into motion automation. Thus learning techniques more effectively when done with a separate exercise schedule. According to Schmolinsky to inculcate a motion pattern to become automatic and naturally occurring it takes a large number of repetitive practices to be performed with significant amounts of time.

Based on the background of the problem can be identified problems, namely: (1) training Pelatnas not based on High Performance Program, (2). The trainer does not provide specific style engineering exercises to improve the mechanics of athlete's motion but is only 
reminded during practice, (3) some swimming pool movement of Pelatnas athletes has not been performed in accordance with the mechanics. Based on that problem formulation is submitted as follows: Is the technical training assistance can have an impact on improving the technical performance of athletes swimming SEA Games 2013.

Research on the swimming branch associated with the effectiveness of motion has been done with a combination of SR (Stroke Rate) and SL (Stroke Length). SR is the speed of force or the number of stroke frequency of the arm while the SL is the length of the stroke arm. Thus, the increase or decrease in swimming speed is determined by the addition or reduction of SR or SL. In previous studies, these variables were used to characterize biomechanics and swimming physiology. Furthermore, Craig and Pendergast argue that the increased swimming speed is generated by the addition of SR by reducing the relatively small SL. Costill et al presents the concept of Stroke Index (SI) which is the result of swimming speed and SL. Kiskinen shows a high positive correlation coefficient of SI with the maximum velocity of pool and SL. Toussaint and Beek argue that SL provides a good indication for thrust efficiency and may be useful for evaluating individual engineering progress.

\section{Method}

This study used the Design of Sports Action Research (PTO) developed from Classroom Action Research by Kemmis and Mc. Taggart. Implementation is planned for 3 cycles, each cycle consists of 3 times face to face. Each cycle consists of 4 activities with cyclical processes, namely: (1) Planing or planning, which contains action plans that will be undertaken to improve, improve, or change behavior and attitude as a solution. (2) Action or action, which contains activities undertaken by the researcher as an attempt to repair, improvement, or a desired change. (3) Observation / evaluation or observation, observation of the outcome or impact of the action taken. (4) Reflection or reflection, the researcher examines the outcome or impact of the action taken. The process of cycling can be described as follows:

The research subject is athlete of Pelatnas SEA Games XXVII / 2013 member as member of Millennium Swimming Pool and practice in Cikini swimming pool Jakarta. Initially there were 4 athletes who planned as the subject but in the implementation of live 2 subjects, namely: Alexis Wijaya Ohmar and Patrisia Yosita.

The instrument used in this study is a drill for style improvement by considering the subject deficiencies in terms of style mechanics, namely: shark fin drill, thumb drill touch the axilla line, and drill angle manus 35 degrees.

Data collection is done by providing drillstyle improvement training to the subject. Generally the research procedure is described as follows: (1) The preparation stage, namely: (a) Conduct observations before and during the swimming exercise; and (b) Conduct discussions with the coach and the subject regarding the actions to be provided; (2) Implementation stage, namely: (a) Provision of style improvement drill in accordance with the athlete's shortcomings; (b) observe, record, and record, the entire exercise exercise; (c) All activities collected are then described, validated, and interpreted.

The data analysis technique used in this PTO research is descriptive analysis. The process of descriptive data analysis refers to the visual observation of researchers based on mechanics.

\section{Results}

Based on the observation and analysis of Pelatnas athletes during the 3-cycle style improvement exercise and divided into 8 meetings indicates that the application of style improvement drill exercise can improve the athlete's performance to improve the mechanics of the swimming style. Performance improvement indicators can be seen from the change in subject behavior between cycle I and III that have increased. The subject's response and attitude also indicate a change between before and after the study (see and compare between Figures 1 and 6 with Figures 7 through Fig. 12). The results above are in line with theories that force-styling exercises should be done alone when athletes are not tired and must be continuously performed with significant time allocations.

The success of the method of strengthening exercise in improving the performance of the athlete pool, can not be separated from the seriousness of the subject in running the material in accordance with the provisions that have been mutually agreed. The exercise program as the researcher's guide has been prepared and well prepared by researchers and trainers. Trainers 
also give attention to the subject to participate actively is by inviting the subject to discuss about the material exercises done and shortcomings while doing drill movement. At this stage the subject asks the purpose, the benefits, and the way of practice. During the process of this exercise, subjects are always controlled to know the success of the style improvement exercise. Every 2 doses of exercise doses are changed to increase the workload. Implementation of this exercise so that subjects can get the quantity of exercise to do more and try so that it becomes an automated movement.

In cycle one when given body rolling exercises with free shark fin drill, bottom sweep with a 35 degree angle manus drill, and recovery with the thumb drill touch the axilla line the subject has difficulty performing and his movements are still rigid as this first exercise is done first. The indicator shown in the body rolling shoulder movement has not been seen coming out of the water (Figure 1 and Figure 2), in the recovery movement it is known that the thumb has not touched the axilla line (Figure 3 and Figure 4), and when performing the initial sweep down movement, the hand has not facing the lower rear (Figure 5 and Figure 6). After being given strength training exercise as much as 8 times of practice seen a significant change.

At the 2nd meeting of cycle 3, there was a significant change of motion force. The indicator is visible on the body rolling of the shoulders already visible out of the water (Figure 7 and Figure 8), in the recovery motion known the thumb has touched the axilla line (Figures 9 and Fig. 10), and when performing the initial movement of the sweep down the visible joints of the manus / the hands have formed a good angle by facing the lower rear (Figure 11 and Figure 12). This is certainly because after undergoing 8 times with increased doses, the subject becomes accustomed to the movement. If the subject is doing the wrong move then the researcher directly correct and give instructions how the movement should be done. Thus the subject will not make the wrong movement on an ongoing basis.

With many tried the right movement of course the movement becomes motion of automation so that the subject is expected will not perform and repeat the wrong movement. During this phase the error of the technique must continue to be addressed and the subject seeks to perfect the movement pattern and minimize or eliminate the technical deficiencies. In the later stages of engineering learning, subjects begin to implant movement patterns so that skills become automatic and natural, requiring a large number of repetitive practices done with significant amounts of time. Learning techniques is a process whereby an athlete acquires mechanical skills, refines his skills, and then accustoms his skills into motion automation.

The drill-style drill training with the mentoring model proved able to improve the style mechanics performance of swimmer member Pelatnas XXVII / 2013. Due to the negative effects of fatigue on the development of techniques, it should be emphasized that technical training should be given with low intensity and at special times before strenuous and exhausting physical exercise. Technical training can not be done simply by reminding athletes on the sidelines of high quality practice with high intensity. Athletes must constantly strive to build the perfect technique to create the most efficient movement patterns. The more perfect this technique is biomechanically the athlete will be more effective in doing the motion and more efficient in the use of power.

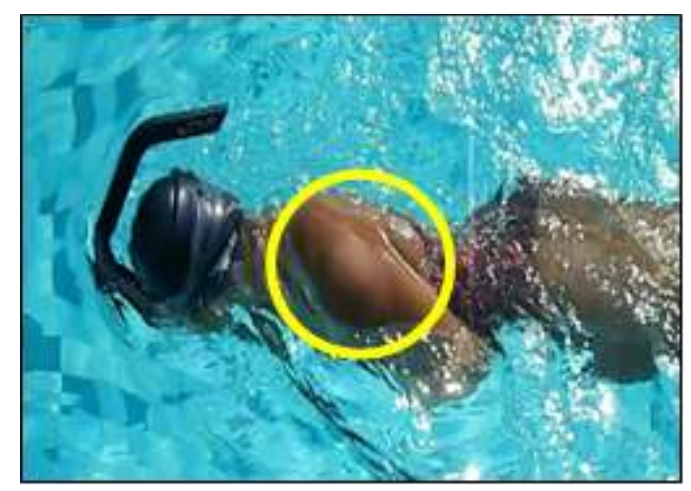

Figure 1. Body Rolling Yosita

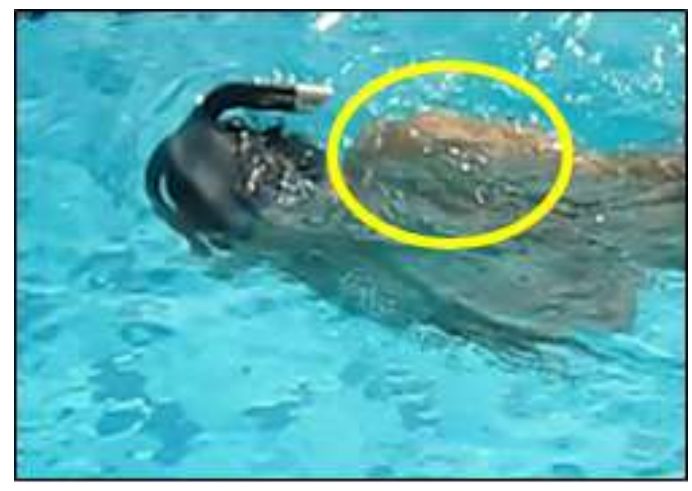

Figure 2. Body Rolling Alexis 


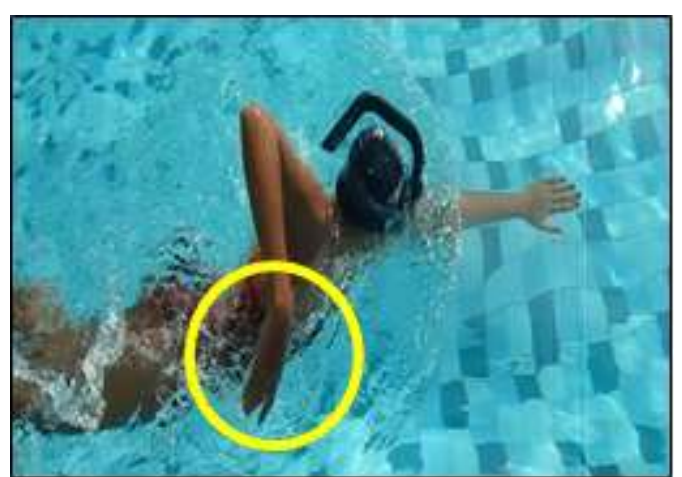

Figure 3. Recovery Axilla Yosita

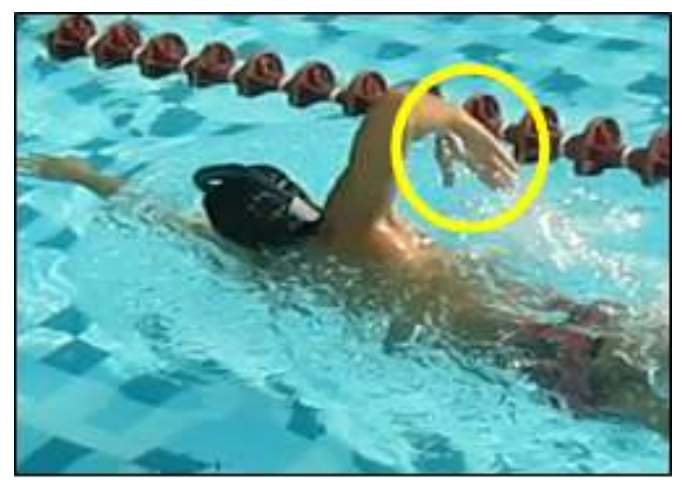

Figure 4. Recovery Axilla Alexis

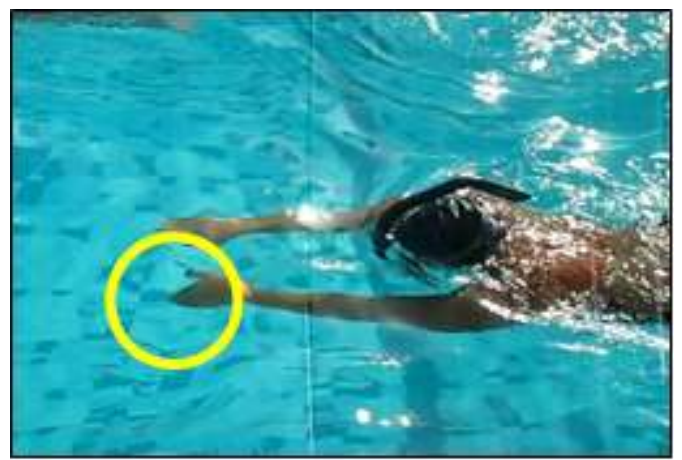

Figure 5. Sweeping Down Yosita

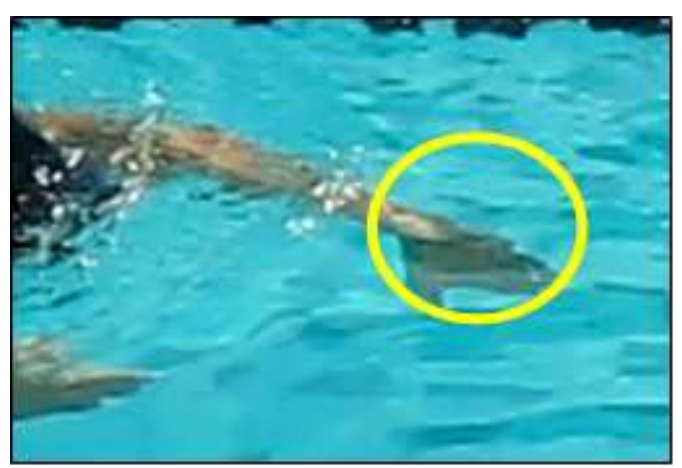

Figure 6. Sweeping Down Yosita

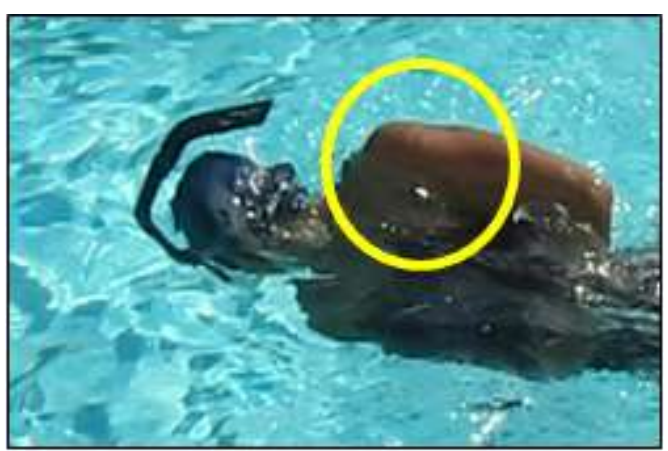

Figure 7. Body Rolling Yosita

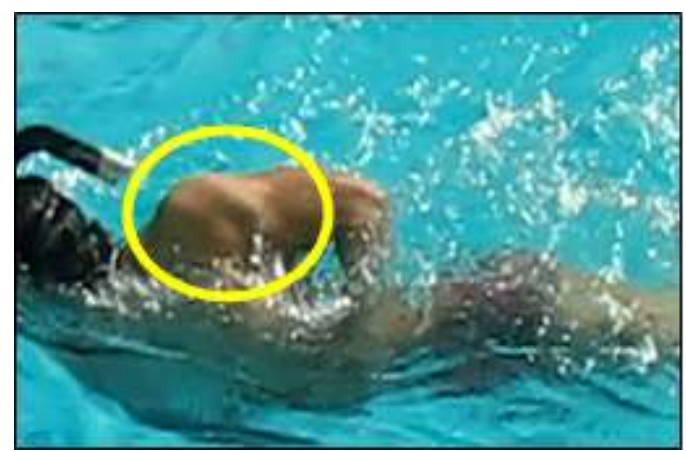

Figure 8. Body Rolling Alexis

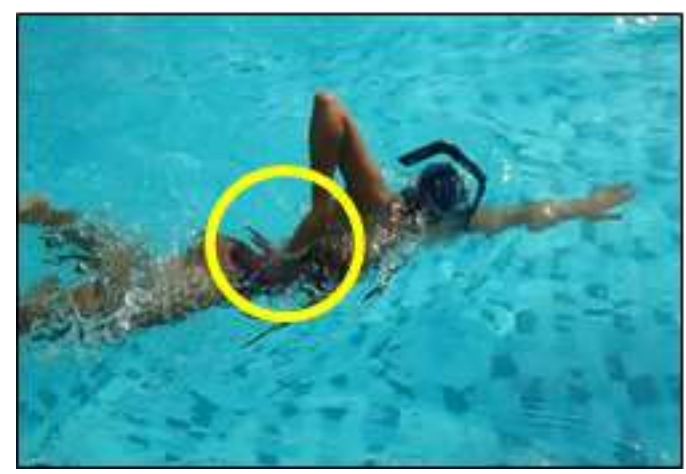

Figure 9. Recovery Axilla Yosita

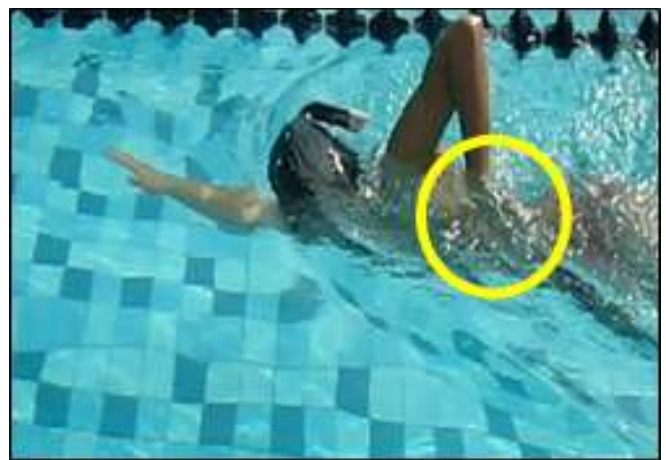

Figure 10. Recovery Axilla Alexis 


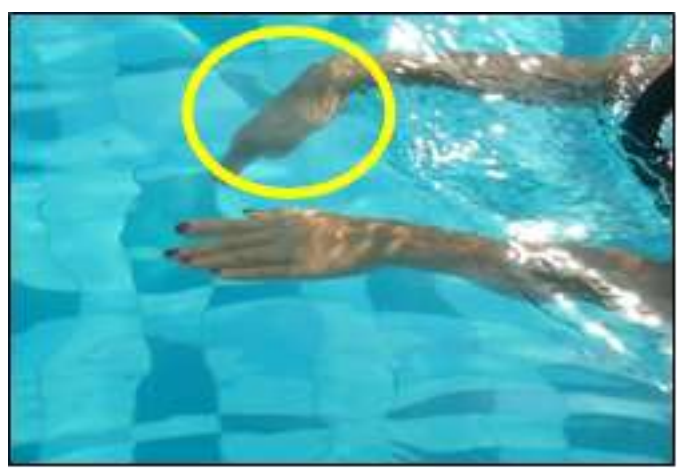

Figure 11. Angle of Manus Cross Yosita

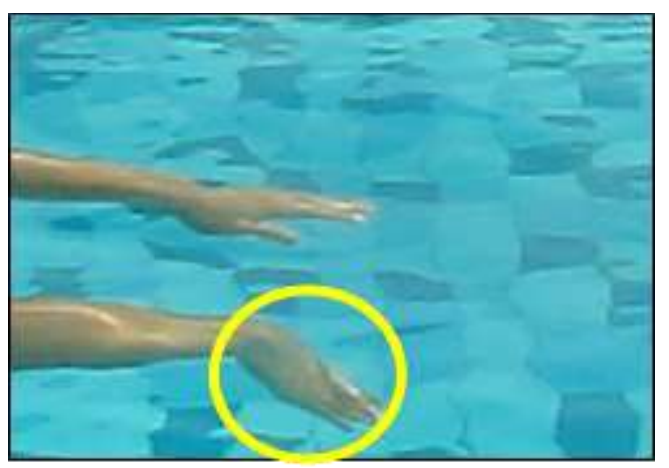

Figure 12. Angle of Manus Cross Alexis

\section{Conclusion}

Based on the analysis and interpretation of visual observation and general discussion, it can be concluded that the model of style improvement exercise can improve the performance of swimming athletes Pelatnas XXVII / 2013 with indicators, among others: (1) Shark fin drill can improve body rolling motion; (2) Drill thumb touching the axilla line can improve recovery; and (3) The 35-degree dung joint drill can correct the initial sweep.

\section{References}

Dick, F.W., 2002. Sports Training Principles. London: A \& C Blank.
Bompa, Tudor O., dan Haff, G. Gregory. 2009. Periodization Theory and Methodology of Training. Kendall Publishing Company: Human Kinetics. Schmolinsky, G., 2004. Track and Field: The East German Texbook of Athletic's. Toronto, On, Canada: Sports Book Publisher.

Craig, A., dan Pendergast D.R., 1979. Relationships of Stroke Rate, Distance per Stroke, and Velocity in Competitive Swimming. Journal Medicine Science Sports Exercise, 11: 278-283.

Craig, A., Skehan P.L., Pawelczyk J.A., dan Boomer W.L., 1985. Velocity, Stroke Rate, and Distance per Stroke During Elite Swimming Competition. Journal Medicine Science Sports Exercise, 17: 625-634.

Tossaint, H.M., dan Beek P.J., 1992. Biomechanics of Competitive Front Crawl Swimming. Sports Med, 13: 824.

Costill, D., Kovaleski, J., Porter, D., Kirwan J., Feilding R., dan King, D., 1985. Energy Expenditure During Front Crawl Swimming: Predicting Success in Middle Distance Events. International Journal of Sports Medicine, 6: 266-270.

Keskinen, K.L., Tilli, L.J., dan Komi P.V., 1989. Maximum Velocity Swimming: Interrelationships of Stroking Characteristics, Force Production and Anthropometric Variables. Scand $J$ Sports Sci, 11: 87-92.

Kemmis, S., dan McTaggart, R., 1998. The Action Research Planner. Geelong, Victoria: Deakin University Press. 